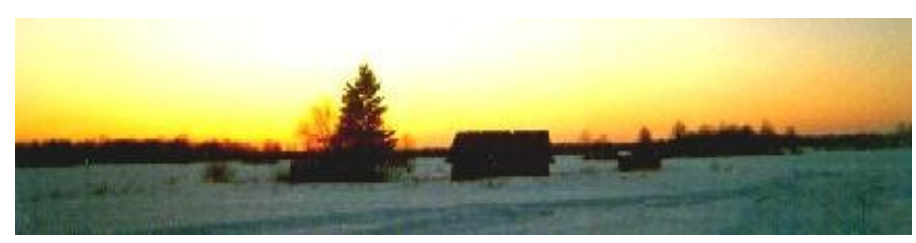

Jätkame eelmises Mäetaguste numbris alustatud matka Siberi eesti asundustesse. Kuid see pole seesama reis, pole seesama koht ega aeg, teised on ka osalejad ja kirjutaja. Tõsi on vaid see, et jälle ollakse teel, seekord Omski oblasti Tara kreisi küladesse: väikestesse, eelmisesajandilistesse ja eestikeelsetesse. On 1996. aasta varakevad ning edukalt ületatud Irdi ehk Irtõshi jõgi. Niisiis 13 valitud päeva Siberis ehk

\title{
Me elupäiväkese
}

Astrid Tuisk

Pühendan oma reisikaaslastele Anu Korbile, Ell Vahtramäele ja Aivar Jürgensonile.

\section{Märtsikuu 28. päev}

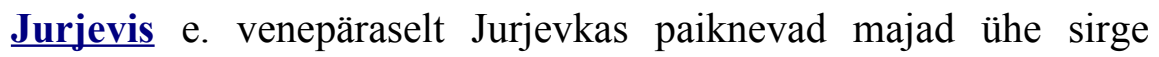
tänava ääres, mõnel pool venivad vahed majade vahel päris pikaks. Küla ühes otsas asub surnuaed, sealt teise küla otsa üle küngaste on umbes poolteist kilomeetrit maad. Kahele poole maju jäävad metsad. Küla keskel asub pood, mis on vaid mõni päev lahti. Ka täna koguneb rahvas sinna, sest on oodata leivaautot. Teeme külarahvaga tutvust, üllatavalt kergesti võetakse meid omaks. Nagu välja

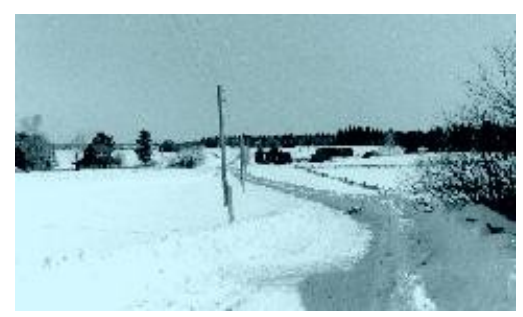
tuleb, polegi külas suurt rohkem rahvast, kui täna poodi tulnud. Jalutan surnuaeda. Aiaga piiratud puudesalu alt sügavast lumest paistavad välja puuristid. Mõnel lehvivad küljes värvilised pärjalindid, ühe risti peal on kommid. Matusseaia mäest alla vaadates märkan laiade lumelaudadega sõitjat.

Alma ja Viktor Jaska maja väravas lõhub peremees puid. Pererahvas on kohalik, Viktor sündinud siit 15 kilomeetrit eemal huutori peal, Alma elanud siin kogu oma elu. Hooned ongi Alma isa ehitatud. Majas jagab vahesein ruumi kaheks - toaks ja köögiks. Ukse vastasnurgas paikneb suur ahi. Nurgas põriseb külmutuskapp, selle kõrval on laud ning puhvetkapp, toolil veeämbrid. Seina peale on kinnitatud krapp. Toaukse ees ripuvad kardinad, nende vahelt paistab televiisor ning suur kirst, kust perenaine käib mulle näitamiseks kuivatatud taimi otsimas. Seinad ning ahi on tavapäraselt valgeks lubjatud, värvitud põrandatel kaltsuvaibad. Toapõranda all on koobas, sealt ilmuvad välja moos ja kuremarjad. Mind palutakse kööki ning jutuajamise kõrvale pakutakse süüa suppi ja paksu piima ja saia ja moosi ja lõpuks veel tsaid. Viktor räägib kohalikust elust, kadunud eesti küladest Silimist (Selim), Immusest ja Novokoskist (Novikovski), aga ka muust - näiteks olevat elekter Jurjevisse sisse pandud 1960ndal aastal ning et Novokoski kolhoos kandnud nime Punane Kütt. Tema isa oli võrokene, rääkis teistmoodi kui teised, ka Viktori ning tema venna Nikolai kõne erineb teiste külaelanike omast, kasvõi rohke vokaalharmoonia ning sõnalõpulise larüngaalklusiili poolest. 
Nagu Siberi karuse kõneliva, ütleb ise. Viktoril on kavalad silmad, usundi juurde jõudes jutustab küll sõnadega arstimise loo, ent võtab seejärel mütsi ning läheb õue puid lõhkuma. Alma on jutukas. Kuigi pole rahul praeguse eluga - lapsed linna kolinud, osta midagi ei jõua, küla jääb tühjaks - ütleb siiski, et kui saakski noorust tagasi, ei võtaks. Tuda tüüd läbi tetta, tuda raskust ma küll ei taha. Tuи hirmus tü̈̈. Üüsel oll tü̈̈ ja päeval oll tüü. Iga päev alates 13. eluaastast pidi kell neli hommikul üles tõusma ning magab veel praegugi hommikuti seda väsimust välja. Alma, nagu mitmed siinkandis, pole päevagi koolis käinud. Ikka kaldub jutt selle peale, et oleks võinud ka kuskile mujale elama minna, aga siia sai jäädud ja siin tuleb elada. Üllatavalt päevakorraline teema. Õhtul on meil pahandus majas - perenaine purjus, lehmad lüpsmata. Ööbime siberi- (või eesti- või vene-) päraselt - kaheksakesi ühes toas.

\section{Märtsikuu 31. päev}

Meile koguneb hulk Jaskasid, kes kõik tahavad mänge demonstreerida. Asume Ritsikut söötma. Asi kujuneb niivõrd spontaanseks, et demonstreerimisest pole enam märkigi. Milda teene on suuresti meeleolu loomine. Mängu teavad nii noored kui vanad. On tõeliselt lõbus. Vennad-Jaskad ei suuda lõpetada, kuigi Milda juba kapsaid-kartuleid lauale kannab. Viktor haarab Anu kaenlasse, et ikka näidata, kuidas tikku suust-suhu edasi anti. Venemaal on tulemas presidendivalimised, vaidlus selle üle, keda valida, on äge: Milda pahandab veel tükk aega järele. Kostuvad nimed Jeltsin, Zjuganov, Ozerov.

Lahkume Jurjevist. Poja pere otsustab Tarasse tagasi sõita homme hommikul vara, kui teed ja ka Irt on veel jääs. Jälle on Milda see, kes hirmutab, et nad ikka lähvad üle Irdi, kes pääseb üle, kes kukub sisse. Tõsi on sellest vähemalt niipalju, et igal aastal mõni Irti jääb, seekord räg̈gitakse mitmest õest. Tõsi on ka see, et Jurjevil ning teistel küladel katkeb mõneks ajaks ühendus rajoonikeskusega. Kuid siinsed naturaalmajanduses elavad inimesed on sellega harjunud, nentides vaid, et väljasaamine ja sissesaamine om rask.

Sõidame bussiga Unaru, sest siin peab elama perekond eestlasi. Olga Vilp elab poja Ärmani ja tema naise Polina juures. Polina on venelane, kohaliku kooli õpetaja ning eesti keelt ei räägi. Parasjagu on külas ka Olga tütar Salme. Kuuldes, et meil öömaja vaja, soostutakse meid kohe vastu võtma. Hea kombe kohaselt pannakse meid televiisorit vaatama. Pakutakse võileibu süüa, ka poepräänikuid ning konservvorsti. Perenaine kaebab pärast tasakesi: Nitshego ne jeli, naverno ne nravilsja. On see kombe pärast öeldud või siiras mure, arusaamad söömise rohkusest lähevad meil nendega igatahes lahku. Salme räägib imestusega, kuidas Eestimaal 5 päeva mitme inimesega poolt liitrit viina joodi ja siis kah ei jõutud ära juua. Siiras mures ollakse ka meie majutamise pärast. Meile vabastatakse kaks tuba, pererahvas kolib kolmekesi ühte tuppa, Aivar pukseeritakse miskipärast magama naaberperesse. Hommikul leiame oma kummikud ahju otsast, sest perenaine on need õhtul ära pesnud. Vanaperenaine, Olga Vilp on sündinud Eestis, Sultsi külas. Meenutab seda: Õkva ku praega näe toda kotust, mul on ta kõik nagu silmin too kotuss. Mammal on ää miel veel! kiidab tütar. Kahekesi nad siin külas eesti keelt räägivad. Üks siin elav Ärmani lapselaps kannab nime Tõnis. 
Alma Papakoi tuleb meile juba esimesel õhtul külla, edaspidi kujuneb see tavaks. Sündinud on ta Tonskis. Kodus leidub Almal vanu raamatuid, nagu Risti-rahva palve koda 1891. aastast, Lauluraamat 1901. aastast, Uus Testament jm. On ka 1957. a. aabits, kust Alma õppis eesti keelt lugema. Eestist telliti Eesti Naist. Nurgas on vana Singeri õmblusmasin. Sel ajal kui Anu vestleb, kirjutan ümber Taevakirja, päris vanana tunduvast originaalist, mille endale saamine ei õnnestu. Oleks ju hea masinal kopeerida, kuid siiski ei igatse taga tänapäeva tehnikasaavutusi, minidisc mõjub külamiljöös juba piisavalt kohatuna, ühes kohas küsitaksegi meie mikrofoniküünitamise peale, et kas see on teil nagaan.

Kolonka, kaevu juures tõstab nõudega vett kelgu peale Oskar Liiv. Lähen temaga kaasa Kondiotsa, küla lõppu. Kodus on ka Milda, tema naine. Majas on

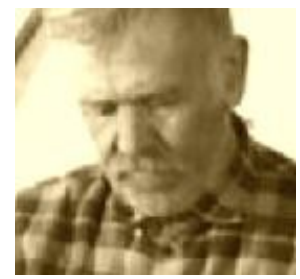
kamber ja köök, madal pliit ning ahi, mille soemüür soojendab ka tuba. Toas seisavad traditsiooniliselt seina äärtes reformvoodid, ühes nurgas ka, samuti tavapäraselt, kummut.

Huvitav, mis kola küll meie oma mööblilaegastes hoiame ning milleks meile neid asju vaja on? Seinal ripuvad laste koloreeritud pildid, nurgas tikitud käterättidega ümbritsetud väike ikoon. Kummutil seisab isegi raamatuid. Neist ühest, Kniga pamjati, mis sisaldab viimases sõjas Omski oblastist surmasaanute nimekirja, leiame tuttavaid perkonnanimesid Jurjevist, Lillikülast, Estonkast, osa neist langes näiteks Sõrve sääre lahingutes. Niimoodi jõuti tagasi Eestimaale. Oskar ja Milda räägivad eestlastest, kes sõja ajal siia saadeti: kes sõja eest pakku, kes tervist parandama. $A$ me elu om siin. Siin me oleme nakanu, siin me lõpetame, ütleb Oskar aktsenditus eesti keeles ning märgib: Iks me oleme tõemeeli eestlase, no oleme läinud juba vene muodu peale. Need palkmajad kannavad endas eestlaste saatusi ning kui ükskord jäljetult kaovad, nagu vundamendita majad ikka, jäävad Venemaa küngastele järele vaid põderlilled, orjavitsad, vene tähtedega eesti nimed paamjatnikele ning kuskile digitaallindistused, mida Internet üle maailma laiali kannab. Praegu istun aga Liivide köögis ning Raadio Rossija: Rossija rodnaja moja saatel ponnistan äsjalüpstud piima juua. Taks ja Pusok hauguvad üksteise võidu.

Õhtuti koguneb Liisi juurde omatahtsi väike seltskond: Papakoi Alma, Palu Liisa ja Jänese Olga. Olenemata meie sealolust on Liisi maja kooskäimise kohaks. Muidu jutukas Liisi kuulab mõnuga teisi. Kui järg jõuab muistendite jutustamiseni, elab ta neile kogu hingest kaasa. Juhtumisi mainime, et kuulsime selle külaotsa pilkenime. Seltskond läheb põlema. Mis nad ütlesid? Ah Kondiots! A me ütleme jälle promlase, prommi-ots. Hoos olles unustatakse aeg ning juba ammu on pime, kui Ell koju jõuab ning tädid selle peale ärkavad ning end lauluga minema asutavad.




Astun sisse väikesesse majja küla serval. Umbes 30 aastane Elfriede Losnikova on sündinud Lillikülas, elas mõnda aega mujal ning tagasi tulles on hädas sellega, et talle ei taheta enam head maja anda. Nii kurdab ta küsides, kas meil pole võimalust seda lehte panna. Elfriede hobiks on väljaõmblemine, pildistan ning vaatan tikitud linu, padjapüüre, käterätte. Elfriede viib mind oma ema Maali Jaugi ning tema mehe Oskar Jaugi juurde. Ka siin on pea sama eestipärane kui Liivide juures, vaid veidi kärarikkam, venekeelsete sõnade rohkem ning kirevam - uksekardinate, riiete ning voodikatete poolest. Sümpaatselt kinnine pererahvas, nii alustame mängudest, jõuame ämariku äbendamise ning räbalikaupmehe kaudu usundini. Nagu eesti keeles kirjutamise, nii ka oma usu on Maali endale selgeks teinud vaid külarahva toel. Opi elust enesest, see on tõsi igavest. Suure habemega Oskar hakkab lõunat nõudma, selleks pakutakse sülti. Kuigi päike paistab, seotakse mulle kojuminekuks pähe kirev rätik, sest Siberi aprillikuu algus pole palja peaga käimiseks tõepoolest kuigi kohane.

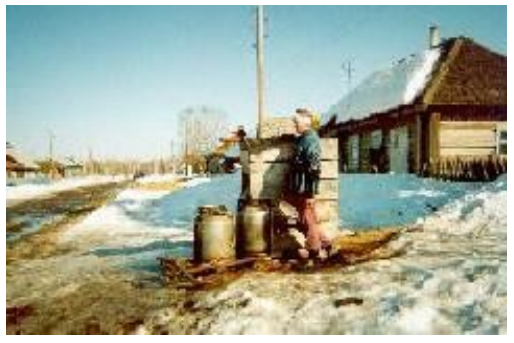

Lähen kaasa Aivariga, kes otsustab kolonka juures filmida. Seal on meeleolukas, kõik liikumas: rahvas, hobused, traktorid, lapsed, koerad, kelgud, veetünnid. Päev paistab ning kogu elu käib ikka eesti keeles.

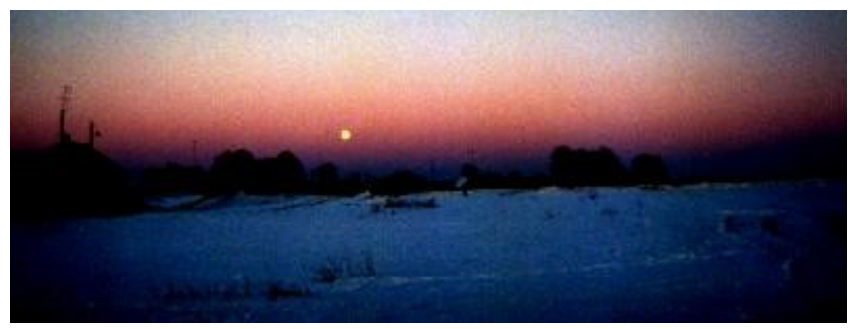

Väljas on täiskuu. Ja nii vaikne, et kõrvus hakkab kumisema. Ainult koerad hauguvad. Kukk, keda me lauta sisse ei saanud, kireb lakas. 
Ärkan üles ning kuulen, kuidas Liisi, ise vahetpidamata rääkides ahju kütte paneb ning kuidas Aivar nõusid kelgule tõstab ning vett tooma läheb. Ikka hea, et ei pea ärkama halogeenlampide valguses ning Orase kraanide pahinas. Ell, muide, öösel silmi lahti tehes nägi, et voodi ees seisab, õieti lamab, üks meesterahvas ning et too ajab teda koha pealt ära. Ellu magamiskoht olevat enne majaperemehele kuulunud.

Lähme kõik koos Liivide juurde korvikudamist filmima. Oskari tehtud toomingavitstest korv maksab külas 50 tuhat. Liivid on ühed neist, kes siinsete hädade keskel (joodikuid, vigaseid palju, hiljuti oli koolilastebuss avarii teinud, palju lapsi sai viga) kannavad Lilliküla helgemat nägu, vaimsust. Ja kui elu siin on paljuski naiste vedada, siis Oskar on erand. Siin on mõnus olla, headust õhkub neist mõlemast ning pole kartustki, et oma austust vastuvõtjate vastu peaks tõendama viinapitsi kaasabil.

Otsustan täna looderdada, jään koos Liisiga koju. Lähme koobast lahti kaevama. See asub maja taga künka peal. Siitpoolt paistavad majade taha jäävad aedadega eraldatud maalapid. Liisi hakkab põhu, laudade, riietega kaetud koobast avama, muretsedes, et kas sai ikka sügisel nii hästi kaetud ja kas lumevesi pole sisse läinud. Peletan eemale ligikippuvaid õhvakesi, lambaid ja muid loomi. Koopasse pandud peedid, porgandid, kaalikad on kõvad ning värsked nagu sügisel. Toas asume juurvilju puhastama ning keetma. Köögis pole peale igeriku kapi ning seinariiuli muud mööblit. Üle köögi lae on kaselatt, kuhu vajaduse korral saab lappe riputada. Ka seinapragudesse palkide vahele saab asju panna. Kivist pliit on madal, pikk, soemüür ulatub tuppa ning jagab selle kaheks. Pliidirauad käivad ära, tagapool on suur pada, kus keevad kartulid loomadele. Liisi otsib kapist suure kausi seest rasva, tütre toodud õli tema ei kasuta. Samuti räägib ta tütre tehtud peedisupist, mida tema teha ei oska. Ainukesteks elektrilisteks masinateks Liisi majapidamises osutuvad külmkapp ja krapp, mööndustega võib nende hulka lugeda ka eeskojas seisva gaasipliidi. Filmimise ajal võtame välja ereda lambi, selle peale saavad kärbsed shoki, iga väikese aja tagant tuleb lamp välja lülitada ning sinna lennanud kärbestest puhastada. Ka on vähe lauanõusid. Selle põhjuseks pole mitte materiaalne kitsikus, vaid joodikust poeg, kes kõik, mis kätte saab, maha müüb.

Sellised välised pisiasjad ei takista Liisit külalistest rõõmu tundma. Praktiliselt kogu aeg rääkiv Liisi on oma usu ja eluvaadete avaldamises kinnine, jutuks tulevad vaid lapsed ning möödaminnes mainitud teated: Ei ole ilma pää pääl, kui Taivaesä ei tiiä. Vot. Nii om me elupäiväkese. Tie alati ommikul rist ette ja loe palvekene ära ja ütski alb ei saa sulle tulla, kellegi viha. Tee rist ette ja ära $v a n d u$. Need teadmised, see eluvaade toetub traditsioonilisele - kõik on toimunud, nii seletatud, eksimus toonud aastasadu ning toob ka praegu kaasa karistuse, hea saab tasutud. Üldse sai Liisilt rahvaluulet kirjutatud autentse situatsiooni käigus. Näiteks Aivarile, kes trepil istub, kordab ta sageli, et enne jüripäeva palja peaga ei tohi istuda, üks oli olnud, kooles är'ki. Kui kuu peal mustad laigud on, räägib Liisi muistendi vaesestlapsest, kes koos kaalpuiega sinna tõsteti. Liisi ei loe lindile ka õhtupalvet. Lilliküla silmahakkav eestikeelsus on ehk seotud ka muu eestipärase olemasoluga. Liisi juures oleme me kaitstud kõigi suuremate hädade: jooma- ja söömasundimise, pealetükkivuse ning liigse hoolitsuse eest.

Õhtul läheme Kondiotsa päikeseloojangut vaatama. Naudime, filmime, pildistame. Teejuhiks Kolja Kakk, Liisi mehe vennapoeg. Kolja vanust on raske määrata, tema staatust külas samuti. 
Kui ühes kohas esitan küsimuse külaveidrikest, siis vastatakse mulle tõrjuvalt, et neid on see ilma aigu ja ennembi oll. Ega siis kõik inimesed üttesugused ei oll. On igasugusid inimesi. Silma jääb nii füüsiliselt kui vaimselt isesuguste rohkus, Kolja on üks neist.

Kolja kutsub meid kluppi, kus tema makimuusikat laseb. Klubis on pime. Silmade harjudes võib eraldada ka tantsijaid, kes hoogsalt tantsu vehivad, kas partnerita või ilma, pole oluline. Samuti pole oluline riietus - dressid, kummikud, joped, kirjud seelikud, nahktagid lehvivad tantsijatel vaheldumisi, üle teiste aga Kolja triibuline suusamüts.

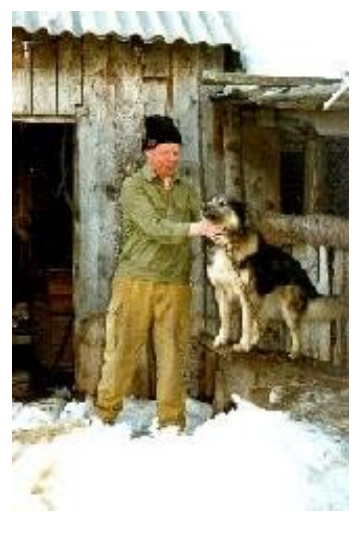

Aprillikuu 7. päev

Maarjapäev, urbepäev, puhkepäev. Keegi ei tulegi urbadega peksma. Liisi kuuleb raadiost, et täna tuleb üheksa urba ära süüa. Aivar käis eile laiade lumelaudadega urbi toomas, Liisi vähendab neid üheksa võrra. Päev algab külalistega ning tõotab jätkata samas vaimus. Liisi poeg Peta Saidangast räägib meiega vene keeles. Sööme Liisi, Ellu ja minu ühisel jõul küpsetatud pirukaid. Võtame ette jalutuskäigu surnuaeda. Must teetriip keset valget lund. Surnuaial on veelgi rahvast, mälestatakse kedagi. Puude all sügava lume sees paistavad mõned ristid. Teeme külaskäigu meie esimesena kohatud Lilliküla inimese Aavle Erna (Erna Aver) koju. Ikka urvad, kausitäis hakklihaks minevat liha, hapukurgid, vene naabrinaine ning eile poest ostetud punane naps. Erna on 36 aastane tugeva kondiga tumedate juustega tõmmu naisterahvas. Tal olevat mure: tema laps sai lastebussiga juhtunud õnnetusel viga, aga sellest ta ise ei räägi. Linde Paul, kes meid juba enne kimbutas, on küla pealt punast viina hankinud ning

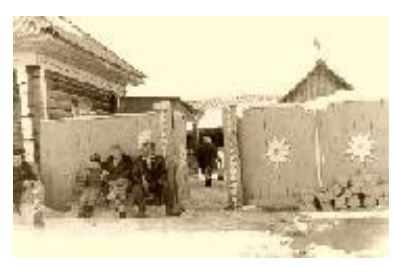
passib nüüd Salme Liivi väravas.

Ega me sealt mööda saa, astume sisse. Läheb suuremaks peoks, lauale kantakse mitut sorti salateid, kapsast, kotlette, muid toite ning muidugi viina. Et on maarjapäev, ei puudu ka ülepanni pannkoogid. Rahvast on palju, segaseks jääbki, kes on pererahvas, kes külaline. Koju jõudes leiame Liisi Karolinskis elava tütre Salme seal pannkooke küpsetamas. Kaasas on ka heledapäine tüdruk ning poiss. On tunne, et täna enam mitte kellegagi rääkida ei taha, Salme pole jutukas ning tema puhul seda ohtu pole.

Valmistume homseks Tonskisse minekuks. Piiripealne Salme Kakk tuleb meid külla kutsuma ning ehmatab, kui näeb nööril pesu kuivamas. Puulba ja pühade ajal ei tehta tööd! Liisi üritab meid kaitsta ning mainib homset ärasõitu.

Viimane õhtu Lillikülas möödub lauldes.

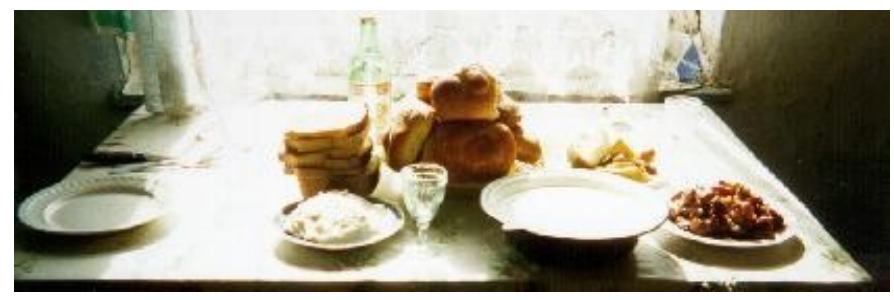


Liisi jätab meiega hüvasti, lihtsalt. Astume mööda jääkirmes teed. Teed ja liikumine on minu jaoks üheks Siberi märksõnaks. Nüüdsest alates jääb unenägudesse Mariinski mustmullatolmuste teede kõrvale ka nilbe ja likke Lilliküla tee.

Tonskis tundub olevat rohkem lund kui Lillikülas. Lumised künkad ja hajali majad. Jälle üks järjest tühjemaks jääv küla. Eemal vaid metsad. Ilm hakkabki muutuma,

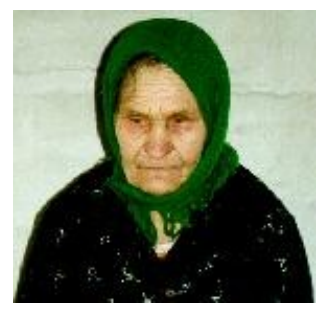
nagu Liisi eile kõneles. Taevas on mõned pilved, kõrred liiguvad tuules. Elfriede Orno laulab ja laulab ja laulab. Viis ei tule küll hästi välja, hääl hakkab ka pikast laulmisest kähisema. Tädi on gripis ega kuule peaaegu üldse. Kuid niipea, kui aru sai, et me laulu tahame,

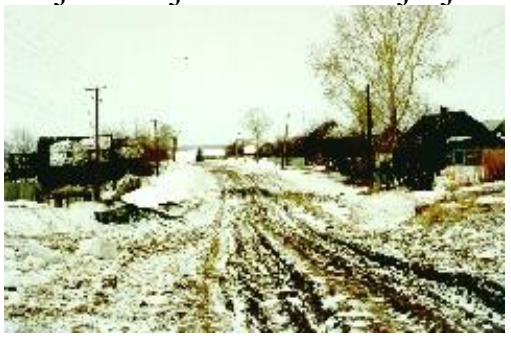
tõusis sängist ning hakkas laulma. Ja laulab ja laulab ja laulab.

Tonsk erineb Jurjevist peale muu selle poolest, et siin on mõned uuemad telliskivimajad. Vanas koolimajas elab praegu Hilda Udras koos oma pojaga. Pärast repliike Mis ma küll teile süüa annan, ei tea ju, kas te sööte, pakutakse suppi ja pakse pannkooke.

Küsime Anuga öömaja Pauliine Talvikult. Väike korras vaipaderohke maja jätab koduse mulje. Nii koduse, kui see Tonskis üldse võimalik on. Pauliine on hea perenaine, küpsetab leiba, teeb sinki, keedab meile süüa. Esimest korda näen laual tatraputru, Kamilla, üks Pauliine õdedest, ütleb imestunult, et tema ei tee kunagi putru. Pauliinel on kokku neli õde, üks neist elab Eestis, kolm Tonskis. Koos Kamilla ja Emmiga nad laulavad, kuigi Pauliine enne teatab, et pärast mehe surma tema enam ei laula. Emmi üritab katmistehnikas kannelt mängida. See on aga korrast ära, nagu Emmigi, kes on purjus.

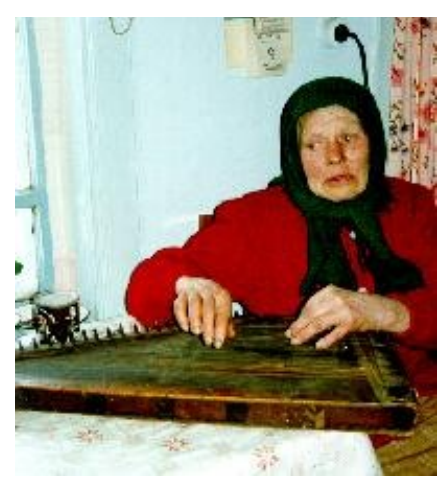

Aprillikuu 9. päev

Kõnnime Elluga küla algusesse, lähme Arnold Kõvaga juttu ajama. Tema naine ei oska eesti keelt, Arnold aga räägib muuhulgas ühe kogumisreisi parema muistendi, mille kuulnud vanamammalt, Kõva Idalt. Meie tuleku üle tunneb headmeelt ning käsib muudkui küsimusi anda. Ell siis annabki. Turske 41-aastase mehega kohtume veel.

Otsime surnuaeda, sajab ja tuiskab lund. Üha enam tundub, et kogu küla on korrast ära, et midagi on lahti nende inimestega. Kes aru poolest tundubki normipärasem, see on lihtsalt purjus. Süngust lisab kahe vaenutseva leeri olemasolu. Käime Elluga veelkord Elfriede Orno juures, seekord süüdistab ta külanaisi enda eksitamises, nii et ta küla otsast enam koju ei osanud tulla ning

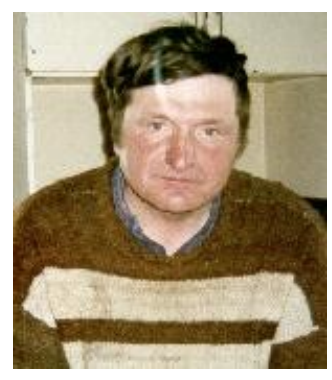
selles, et nad ristinellapäe matusseaias ragusid. Meile ütleb, et me ei kardaks, Jumal on teiega, teile midagi ei tee, vot mis ma ütle. Päevatagune küla. 


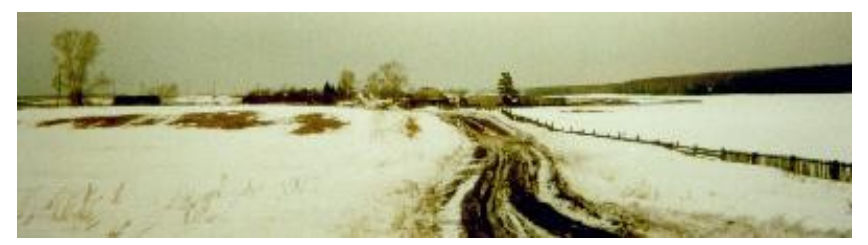

Õhtul laulavad tädid jälle, kolmekesi, õed. Kamilla, väike temperamentne hea sõnaga naisterahvas, ilmub täna välja viinalõhnadega, kommenteerides umbes nõnda: "Elu on selline, võtsin ka ühe suutäie, mis siis minagi enam." Purjutamine ning purjus olek on saamas elu loomulikuks osaks. Pauliine juures elav 12-aastane Natasha teatab justkui muuseas, et hiljuti oli nende muusikaõpetaja joomisse ära surnud. Uksest astub sisse Arnold Kõva. Peale selle, et ta meid segab, ajab ta vihaseks Natasha isa ning see on sunnitud ta välja viskama. Lahkudes heidab ta jääjatele ette matusseaias ragumist. Laulmine jätkub. Kamilla tõmbab mind laulu saatel tantsima, kaks sammu ühele poole, kaks teisele. Ka rahuliku Pauliine sisemuses midagi keeb, mis ta pärast laulmist mööda tuba ringi tantsima paneb.

\section{Aprillikuu 12. päev}

Oleme jälle liikumas. Eile vaatasime ringi Sedelnikovos ehk Telningas. Külastasime Liisi õde Olga Jänest. Olga koristas, oli lihavõtte-eelne neljapäev. Küll ta laulis! Ilusaim hääl minu Siberi-reisidel - pehme, vaikne, veidi kare. Nii mõnigi kord meenutas ta hääl Liisi oma, eriti nende ema laulu Mammakõne ära kuoli... ajal. Pikad, pikad halearmsad laulud. Ja kutsikas muudkui mängis ja päike vajus üha sügavamale Tellingu taha. Ning maailma vaev ja mure, sesse valendusse sureb... Õhtuks jõudsime väsinutena võõrastemajja.

Tarasse! Tara buss on tühi. Loodame teravaid elamusi. Roheline nõglapuumets ja mõnel pool juba lume alt väljas rohelised pohlavarred, sinises taevas särav päike ja ikka veel kiiskav lumi pakuvad neid muidugi. Üle Irdi on tee märgitud, buss ei sõida juba nädal aega üle. Üle tuli küll üks sõiduauto. Hommikul on veidi kahutanud ka, nii et marsime üle Irdi nagu tepi. Vaid eemalolev kõrge liivakallas laseb all aimata sügavat jõge.

Tara, nii ametlikus kui ka kohalikus kõnepruugis linn. Astume hetkeks sisse Linda Saia juurde, kes on aga haige. Sellegipoolest mängib ta veidi viiulit ning nagu eelmine kordki tuleb meid bussi peale saatma. Käime ka Tara muuseumis.

On Suur Reede, buss on puupüsti täis. Oleme Mihhailovkas ehk Pardinovas. Kohutav pori. Istume esmalt Valja Stjuffi juures, kellega bussist maha astudes kohtume ning kes meid teed jooma kutsub. Eesti keelt kõneleb ta pahasti. Lapsena, kui Valja Taras elas, oli ta ainult eesti keelt osanud. Ema oli nii uhke tema üle, et ta nii ilusasti eesti keelt räägib. Vene keelt ei osanud üldse, teised lapsed hakkasid narrima ja tema unustas eesti keele täiesti. Kui nüüd küsiti, kes ta on, eestlane või venelane, vastas Valja kõhklematult, et eestlane. Kuigi räägib vene keelt, on eestlaseks olemine 
ikkagi po dushi, need on veresidemed. Tal on kolm last, vanem tütar Olja ja poeg Sasa, umbes 16 ringis, teevad kõiki kodutöid ning ainult noorim, Nastja, ei saa eesti keelest aru. Kuigi ka mees on eestlane, räägitakse kodus vene keeles. Eestimaa teadlastega seondub Valjal lapsepõlvemälestus: lapsena sugulaste juures Tonskis viibides tulid sinna Edgar Saar ja Kalju Saaber. Valja meenutab sõbralikku Edgar Saart ning seda, kuidas läbi filmiaparaadi vaadates küla nii ilus ja hoopis teistsugune tundus. Joome teed, vaatamata Valja tegemata kodutöödele. Sest kunagi ei ole nii kiire, et poleks aega tassikest teed juua ning juttu ajada.

Kuigi Valja pakub öömaja, otsustame siiski minna Linda Saia poolt soovitatud Galja ja Villu Purmaku juurde.

Aprillikuu 13. päev

Külas pole pikki sirgeid uulitsaid, vaid on mitu käänduvat tänavat. Majad on ilusad, mitmed neist värvitud ning kaunistustega, nagu Purmakute oma. Siin külas poleks öömaja saamisega raskusi. Elluga läheme Miili Langega juttu ajama. Langesid elab külas mitu õde, nad on sündinud soome külas Larionovkas e. Laarukülas. Mihhailovkasse ongi koondunud ümberkaudsete soome külade Larionovka, Suurküla asukaid ning mujalt eesti ja vene küladest tulnuid. Langed on eestlased, soomlasi ja eestlasi eristatakse, kuigi kõik räägivad eesti keelt. Meie ööbimiskohas saavad kokku kaks soomlast ning hakkavad rääkima vene keeles. Lähme üle tänava Senni Lange juurde. Senni satub hoogu, räägib küüditamisest, järgmisel päeval me teda enam kätte ei saa, küla tõlgendus: ehmatas liigse avameelsuse pärast, pidas meid pioonideks. Majas tuiskab meist välja tegemata ringi vene minia. Külas on kumu lahti, et Eestimaalt siin ollakse, meid tuleb vaatama Pauliine Adamson, kes juttu tahab ajada, hiljem erinevate põhjendustega külaskäigust eemale põikleb. Küla räägib, et tema mõistab nõiduda.

Homme on lihavõtted. Valja Stjuff värvib mune, Aivar filmib.

Poevärvidega saavad munad eredavärvilised: kollased, sinised, punased, rohelised. Valja on küpsetanud kruusi sees saiu, need on üle kruusi ääre kerkinud ning meenutavad kujult seent. Saiades pole kohupiima. Olles toimetustega valmis, tõstab Valja lauale munakausi kõrvale ühe saia: Vot tak stretshajut pashu.

Purmakute majapidamises elektriliste aparaatide puuduse üle kurta ei saa: nurgas plingib sügavkülmuti, teises seisab külmkapp. Keset kööki vasakule jääb vene ahi, selle taha nurka kätepesualus. Tube on kaks, neid kütab kontramarka. Aknad on suured ning neid on palju. Maas ei ole kaltsuvaibad, vaid põrandakate. Kõik on puhas, ka õuepealne laudadest põrand, mida Galja igal laupäeval peseb.

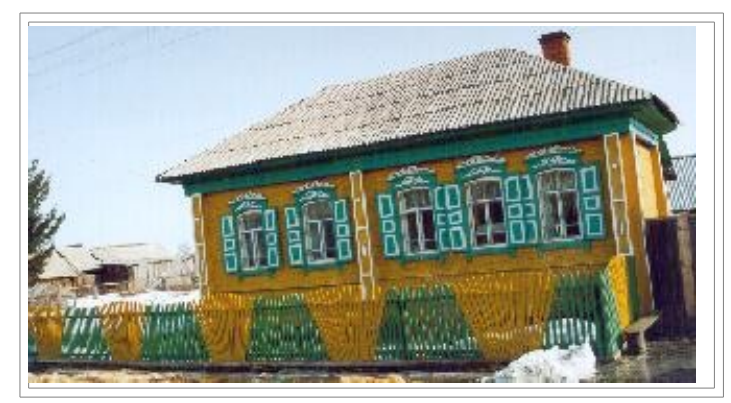


Esimene munapühi. Päev algab lookas lauaga, Galja toidud viivad keele alla. Lähme jälle Valja Stjuffile külla, et jäädvustada munade koksimist. Seal on seltskond koos: Valja, tema mees Volli, Volli Vänter ja tema naine, kõik alla neljakümne eluaasta. Hiljem astuvad korraks läbi Valja mehe vanemad ning vend Viktor, et linna viimase sünnipäevale edasi minna. Jutt käib vene keeles, kuigi Volli/Vova Vänter nimetas end näiteks tshistokrovnõi estonets. Stjuffide peres oskas Viktor samuti enne kooli vaid eesti keelt, kuid nüüd ei räägi üldse. Lauas istuvad peale ühe kõik eestlased, naljaga pooleks küll, kuid tehakse märkus, kui jutt eesti keelele üle läheb. Mune tõesti koksitakse, käsi munaga sirutatakse ette ning ringis proovitakse järgemööda munade tugevust. Kõige viimaseks jääb seekord Nastja.


Söögist ja joogist puudust ei tule, salat, pitsa, riis, vinegrett ja palju muud, vahepeal vahetatakse taldrikud ning siis tuuakse kotletid ja kartulid.

Lõbus on, räägib põhiliselt Volli, muuhulgas anekdoodi (vene keeles): "Kolm meest näevad - jänes hüppab mööda teed. "Näe, jänes," ütleb üks. Aasta pärast lausub teine: "Oli jah jänes." Aasta pärast ütleb kolmas: "Shto võ ssorites, gorjatshie estonskie muzhiki ". Üha sunnitakse meid pitse tühjendama, ähvardustega maja õnne äraviimisest ja pererahva mitteaustamisest.

Väljas surnuaial, mis siin asub küla sees, näeme liikumist. Anu ja Ell on juba avastanud Saiad, kes sinna mälestama tulnud. Ühineme nendega. Kaasas on söök, esimene pits puskarit valatakse papotshka ristile, oma osa saavad ka kõik juuresolijad. Teisi mälestajaid surnuaial pole. Külas soovitakse üksteisele "Hristos voskres!" Guljaitame pühade puhul, õieti hirmust kostitamise ees. Päike, kahutanud tee, sulavesi. Eriti suur lomp on Kaidukkide väravas, kuhu peale mõningast siseheitlust ikkagi sisse astume. Külamehed mängivad seal kaarte, meid nähes lahkuvad ning jätavad kaardid lauale, nii et meil midagi muud üle ei jää, kui ka üks mäng teha. Siin ollakse pidutujus. Minna otsib välja

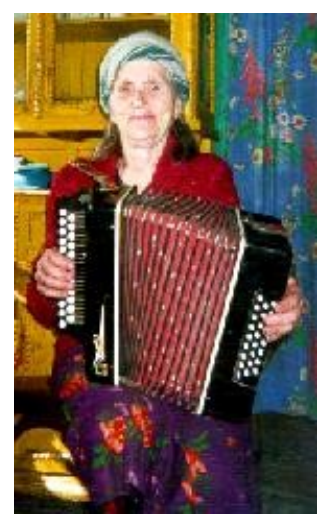
oma garmoshka.

Peremees, Vassili Kaiduk, mainib oma Austria päritolu. Sündinud siinsamas Pardinovas, oskab ta ka eesti keelt. Kostitamisest me muidugi ei pääse. Vassili teeb tule alla ning käsib Minnal meile süüa otsida: kohevad saiad, praeliha, munad, puskar ning põrknatsai. Minna oskab sõnadega ravida. Seda ei pea ta mingiks salateadmiseks, vaid vastupidi - ta räägib just sellepärast, et meid õpetada. Uksest astuvad sisse Tedre Volli ja üks külamees. Volli mängib pilli, Minna laulab kaasa. Tuleb ka Volli naine ning kurdab, et on elanud nii soome külas, venelaste hulgas kui eestlaste juures, aga korralikult ei oska ühtki keelt. Saame kaasa mune.

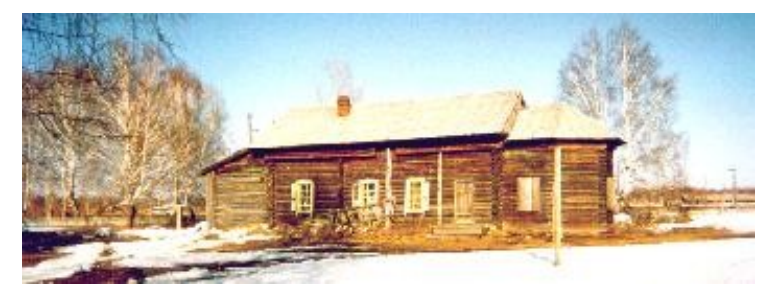

Pildistame endist Lozhnikova kirikut, praegust klubi. Siin on eriti märg, läbi sügava lume vajub vee sisse. Targemad (nagu vastutulevad kuskile peole kiirustavad neiud) vahetavad oma kummikud 
kõpskingade vastu pärast kuivemale pinnasele jõudmist ning saadavad kummikud väikevennaga koju.

Aprillikuu 16. päev

Alustame jälle filmimisega, seekord Linda Saia õe Hilda ja tema mehe Eduard Koka juures. Hilda ketrab, kraasib, laulab ning räägib. Saiade venda Aleksandrit tunti mõni aeg tagasi hästi Eestis, praegu elab ta Omski lähedal. Hilda mäletab opteerumist 20-ndatel aastatel, nende kodu oli üheks selle arutamise kohaks. Mõlemad on olnud kooliõpetajad ning mõlemad on mänginud Linda Saia juhitud ansamblis.

Hilda püstise voki tegi vend Richard Sai, kes elab vaid paar maja edasi. Väike maja erineb juba välimuselt teistest külamajadest. Imeteldav oskus ning tahe puutööd teha: vokke, aknaid, uksi, mööblit, aga ka viiuli on ta teinud. Saiadele omane teadlikkus ning edasipüüdlikkus avaldub Richard Saias heas eestlaste Siberi-asustamise tundmises. Väike kräbe meesterahvas on elus palju läbi elanud, paikseks ning rahulikuks on ta vanuigi jäänud. 86-aastane, a jookseb kak pioneer, ütles keegi talle, selle kohta on tal oma arvamus: Ma olen veikene, kerge, temal on kergem elada. Mul vennanaine oli jäme, suur, temal oli raske elu. Jätan tema pihtimuste kuulamise Aivari hooleks. Maja taga kasvab ounapuid, külma eest maa ligi painutatud.

Läheme uuesti Kaidukkide juurde. Minna otsib välja märkmiku ravisõnadega, kirjutame need maha. Minna teadmised on õpitud häda sunnil: isa jättis talle sõnad. Tausta, palju nn traditsioonilist pole. Nii ta ütleb ka: Mul ei ole olnud, ma ei tea. Ometigi tundub vaid meile, et midagi on poolik, et sellega koos peaks veel midagi olema. Minna ei probleemitse, sest nii, kuidas tema teab, piisab, et sõnad toimiksid. Nüüd ta enam lugeda ei näe ja peas peale roosisõnade teisi pole. Ta on otsutanud sõnad meile edasi anda. Jutuajamine kujuneb asjalikuks ning konkreetseks: millal lugeda kahetu sõnu, kuidas ära tunda, et lendva on, mille peale lugeda roosisõnu jne. Vaiksel häälel lisab ta: Las nad saisva, ku vaja on, siss loet ja ega see enam midagi kurja ei tee. Sellisena moodustab Minna maailm ühtse terviku: pikad ning täpsed jutud Eestimaal käimisest, sellest, kuidas siis, kui lapsed väiksed olid nende juurde pool küla kokku käis, kontramarka, nurgas olev puhvet, roheliste plaatidega maja. Nagu paljud halvasti nägevad inimesed, kummardub ka Minna rääkides hästi ligidale, vestluskaaslast puudutades. Vassili Kaiduk tuleb küla pealt tagasi pudeliga. Hetkeks lootsime, et ta seda ei leia. Mis teha, ka see kuulub Minna elu hulka. Meile kurdab Minna vaid seda, et oma Eestis elavast õest midagi ei tea ning palub, et me talle kirjutaksime.

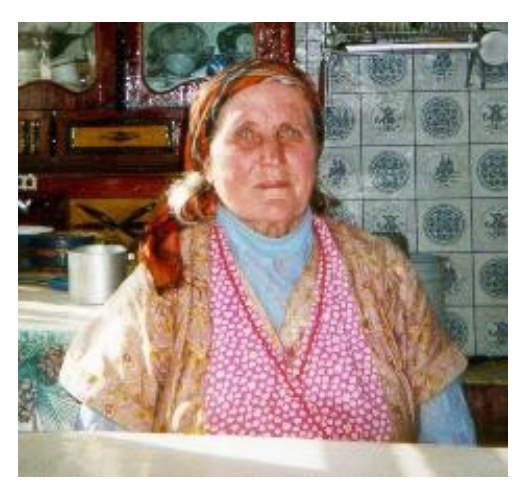

Purmakute naaber Liisi Orover sündis Suur-Silimi külas ning käis kaks aastat eesti koolis. Paljud sugulased läinud Eestisse, oma mittemineku põhjuseks ütleb: Kuigi ma ei taha omast kotust välja minna. Usundist me ei kõnele ning arvan, et mitte sellepärast, et seda ei teata, vaid vastupidi: teab ning peab liiga hästi. Kui Jurjevis ning Lillikülas lendavad unkaaukudest puugid praegugi sisse-välja, Tonskis puhusseid pannakse ning keset küla ära eksitatakse, siis ka edumeelses ning materiaalselt heal järjel Mihhailovkas korjatakse jälgi ning loetakse roosisõnu. Vähemalt on veel põlvkond, kes seda teeb. 
On karge päikesepaisteline hommik. Perenaine laseb köögis piima läbi. Koerad ärkavad ja hakkavad haukuma, lapsed lähevad kes kooli, kes lasteaeda. Jälle on aeg istuda hunniku eileküpsetatud saiade ning liha, kartulite, kohupiimaga kaetud laua taha.

Lähen välja, vastu tuleb meesterahvas Davaite poznakomimsja! ja

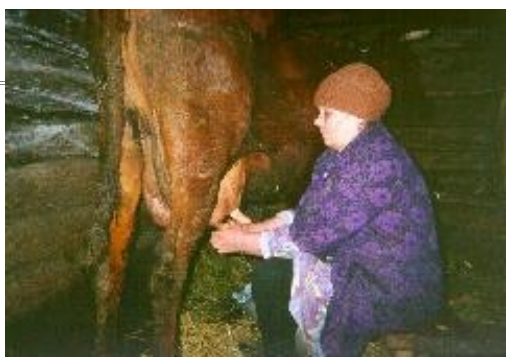
küsib nime. Selle teada saanud, küsib: A kak po russki? Ka see on siin tavaline. Astun veelkord sisse Minna Kaiduki juurde, et jumalaga jätta, kuid kusagil kripeldamas, nagu oleks midagi veel rääkimata. Täna on Vassili kaine ning istub koos pojaga vaikselt köögilaua taga. Ajame juttu niikaua, kuni televiisorist järjekordne seriaal algab.

Lähen koju ning ime küll! Galja laseb esmakordselt meil kodutöid teha - lõikan supi sisse liha ning riivin porgandeid. Sisse astub Ksenja Jaanus ning kutsub kaasa - Minna tahtvat minuga rääkida.

Minnal hakkas süda valutama, kas ta ikka selgitas täpselt, kuidas neid sõnu lugema peab. Muidugi on ta nõus seda näitama, õnneks pole Aivar veel jõudnud välja minna. Filmime. Näib, et kumbki naisterahvas ei taipa päriselt, millega tegemist, sest Ksenja jääb seisma otse kaamera ette ega saa aru minu püüdest teda ära juhtida. Tegemist polegi lavastusega, Minna ei näitle, vaid loeb päriselt, mähib pärast mustad villad ajalehe sisse ning ulatab mulle: Pane karmanide!, sest neid saab edaspidi kasutada.

Igal pool soovitakse meile Hääd teereisi! Teiste viisakusvormelite nappuse kõrval on see üldlevinud. Küla tundub täna õhtul nii omane. On tuuline, päike loojub, koeradki ei haugu, on juba tuttavad, inimestest rääkimata. Lähen mööda tänavat, lapsed jooksevad puulõikamise juurest lähemale, hüüdes Tjotka idjot! ning teretavad mind püüdlikult Zdravstvuite!

Õhtul käime saunas, nagu mitmed Siberi saunad, on seegi meile vingune - Ell


kukub ristiseliti saunalävele maha. Soojendan kontramarka ees varbaid, perenaine peseb köögis nõusid ning vaatab läbi lahtise ukse televiisorit. Mõtlen ajast ning sellest, et nii Siberis, Setus kui Kihnus on kätte jõudnud Santa Barbara aeg.

Matk Siberi eesti asundustesse 1996

\section{Me elupäiväkese}

\section{Fotod}

Astrid Tuisk

Anu Korb

Aivar Jürgenson


Kujundus: (C) cps '97 